\title{
Utilization of a training portfolio in thoracic and cardiovascular surgery: the example of the French platform-EPIFORM
}

\author{
Alex Fourdrain ${ }^{1}$, Charles-Henri David ${ }^{2}$, Lucile Gust $^{3}$, Gilbert Massard $^{4}$ \\ ${ }^{1}$ Department of Thoracic Surgery, Amiens University Hospital, University of Picardy, F-80054 Amiens cedex 01, France; ${ }^{2}$ Department of Thoracic \\ and Cardiovascular Surgery, North Laennec Hospital, Nantes, France; ${ }^{3}$ Department of Thoracic Surgery, North Hospital-APHM, Aix-Marseille \\ University, F-13915 Marseille cedex 20, France; ${ }^{4}$ Department of Thoracic Surgery, Strasbourg University Hospital, Strasbourg, France \\ Correspondence to: Alex Fourdrain. Department of Thoracic Surgery, Amiens University Hospital, University of Picardy, F-80054 Amiens cedex 01, \\ France. Email: fourdrain.alex@chu-amiens.fr.
}

\begin{abstract}
Thoracic and cardiovascular surgery requires learning both theoretical knowledge and technical skills. In this surgical field, several disparities exist between the different training programs around the world. This report describes the implementation of a portfolio in the teaching and assessment of French trainees in Thoracic and Cardiovascular surgery, following an electronic logbook model, aiming to improve the training program. The French surgical course is a twelve semesters' curriculum divided in 3 parts, each part containing knowledge, technical skills and behaviors objectives to be validated, defined by the French College of Thoracic and Cardiovascular surgery. The competencies are marked in the logbook, following a declarative model where the surgical trainee fills every surgical procedure attended (all or part) if he/she has observed, partially or fully performed, or supervised another trainee. All the surgical procedures are linked to theoretical e-learning lessons and each e-learning lesson includes a self-evaluation. This constitutes a competency-based assessment model with milestones both for surgeon trainees and their mentors. This portfolio also contains complementary tools such as an automated publication point calculation, a formatted curriculum vitae generator, and several contact tools between trainees. Implementation of a dedicated portfolio following an electronic logbook model appears to be a relevant pedagogic tool and survey element in the thoracic and cardiovascular surgery training program. Its use may lead to potential educational benefits for the trainee, reliable competency assessment for the supervising surgeon and for scientific society or national college.
\end{abstract}

Keywords: Surgical education; training in thoracic surgery; portfolio; syllabus

Submitted Aug 12, 2018. Accepted for publication Aug 30, 2018.

doi: $10.21037 /$ jtd.2018.08.104

View this article at: http://dx.doi.org/10.21037/jtd.2018.08.104

\section{Introduction}

As a surgical specialty, thoracic and cardiovascular surgery requires learning theoretical knowledge, technical skills, and professional attitudes. Several disparities exist between the different training programs around the world, regarding the length of training, content of the curriculum, the training method and the required skills, as well as the "learning branch" of the trainee: thoracic, cardiac, cardio-thoracic, or general surgeon with thoracic practice (1-3). At a European scale, task forces of the European Respiratory Society and the European Society of Thoracic Surgery encouraged a harmonization of the learning process, and have been working on a proposition of curriculum and assessment of learning outcomes (4). They proposed the use of a trainee portfolio, guided by a curriculum (4). At a National scale, a survey was conducted among French trainees, outlining the need for a homogenous learning process and assessment of competencies (5). Among the different training methods, there is indeed an increased use of portfolios, which are described in the American Accreditation Council for Graduate Medical Education Toolbox of Assessment Methods as a "collection of products prepared by the resident that provides evidence of learning and achievement related to a learning plan" (6). Several portfolio models 


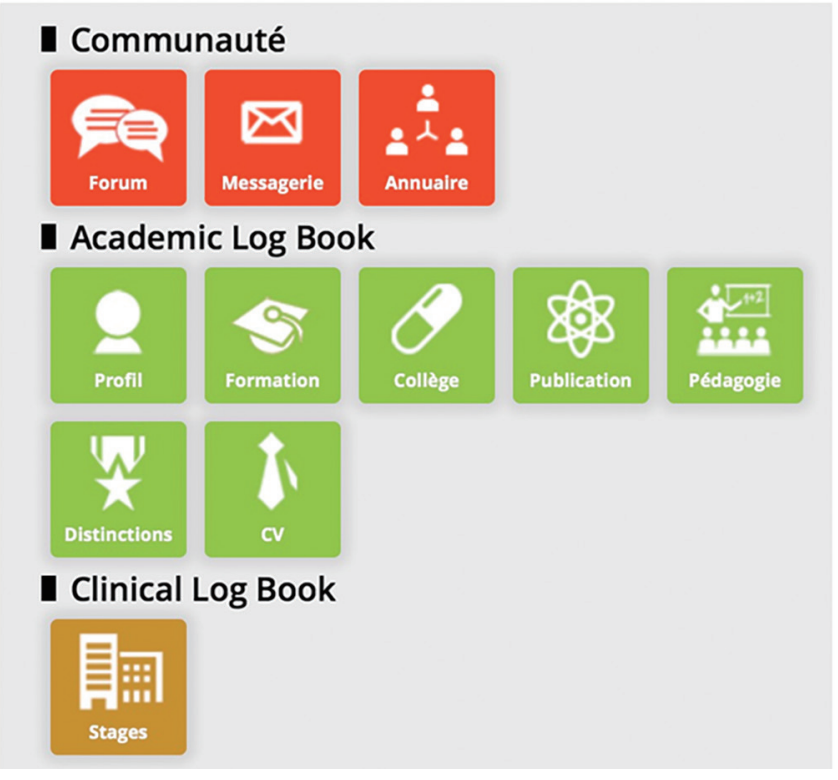

Figure 1 First webpage of the portfolio showing all the features.

have been described in learning and assessing practical skills and knowledge in the field of surgery, including monthly case-report and half-yearly evaluation (7), and dedicated electronic log-book with daily reports under a teacher supervision (8). These studies showed a positive impact of the use of a portfolio in surgical training, providing feedback to the students over their progression, and stimulating them to achieve target competencies $(7,8)$. To date, there is no description of a portfolio in the field of Thoracic and Cardiovascular surgery. This report describes the implementation of a portfolio in the learning and assessment of competencies of French trainees in thoracic and cardiovascular surgery, following an electronic logbook model, with the aim to improve the quality of our training program.

\section{Description}

The French surgical course is a twelve semesters' curriculum divided in three parts. Each part contains knowledge, technical skills and behaviors objectives to be validated, defined by the French College of Thoracic and Cardiovascular surgery and registered in the law. In addition to the specialty syllabus, there is a common syllabus for professional skills and behavior, defined by the French National College of Medical Student, which includes competencies such as communication, collaboration, management, and research. This training portfolio named
Epiform was implemented in 2012, and became mandatory in 2016 to graduate in the specialty. Currently, nearly 140 trainees across the country are using the platform.

This portfolio constitutes more than a logbook, as it contains evidence of every aspect of good surgical care. The electronic portfolio developed by the Association of the Young Thoracic and Cardiovascular surgeons [Association des Jeunes Chirurgiens Thoraciques et Cardio-Vasculaires (AJCTCV)] with the support of the French Society of Thoracic and Cardiovascular surgery [Société Française de Chirurgie Thoracique et Cardio-vasculaire (SFCTCV)] is made of different features allowing to cover all aspects of a surgeon's training, clinical practice, and ongoing career development (Figure 1). It gives the ability to the individual surgeon trainee to reflect on his/her working experience and practice. It also gives a competency-based assessment model with milestones both for surgeon trainees and their mentors.

The competencies for the specialty and the logbook are based on a declarative model where the surgical trainee fills in all the surgical procedures attended (all or part) that he/ she has observed, partially or fully performed or supervised another trainee (Figure 2).

All the surgical procedures are linked to theoretical e-learning lessons, and each e-learning lesson includes a selfevaluation (multiple choice questions, script concordance test...). A mentor is chosen by the trainee every semester, amongst all the surgeon of the institution, which is not necessarily a Professor. This should create a close relationship between the mentor and the trainee, promoting precious feedback between them. At the end, the mentor has to validate the competencies according to the achievement of a certain amount of surgical procedures, e-learning lessons, selfevaluation and behavior in their hospital course (Figure 3).

Several complementary tools were added, such as an automated publication point calculation. It allows for surgical trainee and mentors to have a quick view on the amount and impact factors of his/her publications. The trainee has the ability to generate a formatted curriculum vitae which provides a short summary of all the data compiled in the portfolio: qualifications, professional history, personal details with evidence of the competency achievements, knowledge and personal and professional skills. In order to help communication among trainees there are also contact tools such as a "repertoire", "forum" and mailing.

\section{Discussion}

As our medical environment and surgical practice are 


\begin{tabular}{|c|c|c|c|c|c|c|c|c|}
\hline \multirow[b]{2}{*}{ * O1STERNOTOMIE } & \multicolumn{2}{|c|}{ Observation } & \multicolumn{2}{|c|}{$\begin{array}{l}\text { Partiellement } \\
\text { réalise }\end{array}$} & \multicolumn{2}{|c|}{$\begin{array}{l}\text { Complétement } \\
\text { réalisé }\end{array}$} & \multicolumn{2}{|c|}{$\begin{array}{l}\text { Encadrement d'un } \\
\text { junior }\end{array}$} \\
\hline & 0 & $\Delta \nabla$ & 0 & $\Delta \nabla$ & 0 & $\Delta$ & 0 & $\Delta \bullet$ \\
\hline OIABORD SOUS-CLAVER & 0 & $\Delta$ & 0 & $\Delta \nabla$ & 0 & 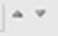 & 0 & 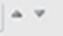 \\
\hline :01 THORACOTOMIE ANTERIEURE & 2 & $\leadsto$ & 0 & 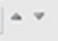 & 5 & $\leadsto$ & 0 & $\leadsto$ \\
\hline O1THORACOTOMIE LATERALE & 5 & $\leadsto$ & 0 & $\rightarrow$ & 6 & $\rightarrow$ & 0 & $\leftrightarrow$ \\
\hline Dif O1 THORACOTOMIE POSTEROLATERALE & 10 & $\leadsto$ & 0 & $\sim$ & 20 & 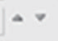 & 0 & 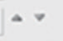 \\
\hline
\end{tabular}

Figure 2 Operative log book regarding surgical approach in thoracic surgery including the 4 progressive steps. Observation: observed; partiellement réalisé: partially performed; entièrement réalisé: fully performed; encadrement d'un junior: supervision of another trainee.

\section{Liste des stagiaires}

\begin{tabular}{|c|c|c|c|c|c|c|c|}
\hline & \multirow[b]{2}{*}{ Stagiaire } & \multirow[b]{2}{*}{ Libellé du service concerné } & \multirow[b]{2}{*}{ Nom du tuteur concerné } & \multirow[b]{2}{*}{ Votre rôle } & \multirow[b]{2}{*}{$\begin{array}{l}\text { Nombre de } \\
\text { stages associés }\end{array}$} & \multicolumn{2}{|c|}{ Validation } \\
\hline & & & & & & Tuteur & $\begin{array}{l}\text { Chef de } \\
\text { service }\end{array}$ \\
\hline 1 & GERAD Junior & Service de Chirurgie Cardiaque Adulte & Vous-même & Chef de Service & 2 & $\checkmark$ & $\checkmark$ \\
\hline 2 & WEBMASTER & Service de Chirurgie Cardiaque Adulte & TETE UTS & Chef de Service & 1 & & \\
\hline 3 & Junior & fsoffsdf & Vous-même & Tuteur & 1 & $\checkmark$ & \\
\hline
\end{tabular}

Liste des demandes de tutorat

\begin{tabular}{l|l|l|l|}
\hline \multicolumn{1}{|c|}{ Stagiaire } & \multicolumn{1}{c|}{ Intitulé du stage } & \multicolumn{1}{c|}{ Statut } \\
\hline GERAD Junior & Essai pour juniorGerard & Acceptée \\
\hline GERAD Junior & Essais Validation prise 2 & Refusée \\
\hline Junior & Période & Acceptée \\
GERAD Junior & Second pour essai validation ctcr.damo & Acceptée \\
\hline
\end{tabular}

Figure 3 Mentor survey screen with trainee(s) under his/her responsibility. Each trainee has validated course (green) or not yet (orange). Liste des stagiaires: list of trainees; liste des demandes de tutorat: list of tutorship request.

changing with the onset of evolving new technologies, it seems relevant to include new pedagogic tools and survey elements into the thoracic and cardiovascular surgery training program. Besides, incoming new technology and innovative treatment strategies need to be added. Implementation of a portfolio has showed great results regarding the learning process in several surgical fields $(7,8)$, and this is the first report of a portfolio dedicated to thoracic and cardiovascular surgery. For a trainee, this electronic logbook presents several advantages: (I) the setting of qualitative and quantitative objectives and practical targets at the different steps of the training program; (II) assessing the evolution of competencies and compare them to a national database. In-training monitoring and selfassessment may reveal insufficient exposure to particular disease areas or surgical techniques in the home institution and motivate in-training mobility towards highly specialized units. For the trainee's referent teacher, this model is useful for: (I) rapid and concise assessment of a trainee's level and prior achievements; (II) advising and helping in the setting of clinical and surgical objectives; (III) a close follow-up with monitoring and "real-time" evaluation of every young surgeon's training objectives. Once again, obviating uncovered topics may help the mentor to advise in-training mobility. For the Scientific Society or Thoracic and Cardiovascular National College, advantages are: (I) setting of a clear training program with defined objectives and their timelines, which appears as harmonized at the national level and guarantees equal quality of training to all trainees; (II) evaluation of training outcomes at a national level, which is an important feed-back for further revision and implementation of the training curriculum; (III) use of this clinical and practice logbook as a validation tool for board examinations. Furthermore, the use of a harmonized 
model within European or International Thoracic and Cardiovascular societies may also lead to an easier evaluation of a young surgeon advancement in the training program, allowing facilitated procedures in applying for scholarships, or exchange programs at an international scale.

Further studies should be performed to confirm the usefulness of this pedagogic tool in Thoracic and Cardiovascular surgery field in the current era. To this end, European trainees and supervising surgeons are looking forward to the report of the task forces of the European Respiratory Society and the European Society of Thoracic Surgery, expected to describe a well-defined curriculum, and to validate a model for assessment of acquired competencies and technical skills, which may most likely be suitable for a portfolio model (4).

In conclusion, the implementation of a dedicated Portfolio following an electronic logbook model appears to be a relevant pedagogic tool and survey element in the thoracic and cardiovascular surgery training program. Its use may lead to potential educational benefits for the trainee, and reliable competency assessment for the supervising surgeon. At the national or supra-national scale, this tools offers control of equity of training, quality of content, and measurement of learning outcomes at a globalized level.

\section{Acknowledgments}

Funding: None.

\section{Footnote}

Provenance and Peer Review: This article was commissioned by the editorial office, Fournal of Thoracic Disease for the series "Training in Pulmonary Medicine and Surgery". The article has undergone external peer review.

Conflicts of Interest: All authors have completed the ICMJE uniform disclosure form (available at http://dx.doi. org/10.21037/jtd.2018.08.104). The series "Training in Pulmonary Medicine and Surgery" was commissioned by the editorial office without any funding or sponsorship. GM served as the unpaid Guest Editor of the series. The authors have no other conflicts of interest to declare.

Ethical Statement: The authors are accountable for all aspects of the work in ensuring that questions related to the accuracy or integrity of any part of the work are appropriately investigated and resolved.
Open Access Statement: This is an Open Access article distributed in accordance with the Creative Commons Attribution-NonCommercial-NoDerivs 4.0 International License (CC BY-NC-ND 4.0), which permits the noncommercial replication and distribution of the article with the strict proviso that no changes or edits are made and the original work is properly cited (including links to both the formal publication through the relevant DOI and the license). See: https://creativecommons.org/licenses/by-nc-nd/4.0/.

\section{References}

1. McElnay PJ, Massard G. Thoracic training across Europe: the trainees' perspective. Eur J Cardiothorac Surg 2015;47:395-6.

2. Reznick RK, MacRae H. Teaching surgical skills—changes in the wind. N Engl J Med 2006;355:2664-9.

3. West D, Codispoti M, Graham T. The European Working Time Directive and training in cardiothoracic surgery in the United Kingdom: a report of the Specialty Advisory Board in Cardiothoracic Surgery of The Royal College of Surgeons of Edinburgh. Surgeon 2007;5:81-5.

4. Massard G, Tabin N, Mitchell S, et al. A harmonized European training syllabus for thoracic surgery: report from the ESTSERS task force. Eur J Cardiothorac Surg 2018;54:214-20.

5. David CH, Debbagh H, Masmoudi H, et al. État des lieux de la formation en chirurgie thoracique et cardiovasculaire en France. Chirurgie Thoracique et CardioVasculaire 2016;20:1-5.

6. $2000 \mathrm{ACGME}$ and ABMS. A product of the joint initiative of the ACGME Outcome Project of the Accreditation Council for Graduate Medical Education (ACGME), and the American Board of Medical Specialties (ABMS). Toolbox of Assessment Methods Version 1.1. September 2000.

7. Webb TP, Aprahamian C, Weigelt JA, et al. The Surgical Learning and Instructional Portfolio (SLIP) as a selfassessment educational tool demonstrating practice-based learning. Curr Surg 2006;63:444-7.

8. Sánchez Gómez S, Ostos EM, Solano JM, et al. An electronic portfolio for quantitative assessment of surgical skills in undergraduate medical education. BMC Med Educ 2013;13:65.

Cite this article as: Fourdrain A, David CH, Gust L, Massard G. Utilization of a training portfolio in thoracic and cardiovascular surgery: the example of the French platformEPIFORM. J Thorac Dis 2021;13(3):2054-2057. doi: 10.21037/ jtd.2018.08.104 